\title{
Sensitivity analysis and thermal performance optimization of evacuated $U$-tube solar collector using genetic algorithm
}

\author{
Hamid R. Moslemi ${ }^{1}$, Mohammad M. Keshtkar ${ }^{2 *}$ \\ ${ }^{1}$ Mechanical Engineering, Islamic Azad University, Kerman 7635131167, Iran \\ ${ }^{2}$ Department of Mechanical Engineering, Islamic Azad University, Kerman 7635131167, Iran
}

Corresponding Author Email: mkeshtkar54@yahoo.com

https://doi.org/10.18280/ijht.360406

Received: 10 April 2018

Accepted: 10 September 2018

\section{Keywords:}

sensivity analysis, thermal performance, optimization, evacuated U-tube, solar collector, genetic algorithm

\begin{abstract}
In order to achieve clean solar energy and utilize this free energy in a useful manner, current research aims at investigation of thermal performance of an evacuated U-tube solar collection, and specifying conditions that lead to development of highest thermal efficiency for the collector. The collector's efficiency is calculated in this work by introducing parameters affecting thermal efficiency including mass flow rate, collector length, and conditions that are mostly environmental factors. Finally, optimal values of decision variables to achieve maximum collector's efficiency were specified using sensitivity analysis results and genetic algorithm. The results show that the collector's efficiency would be increased by increasing thermal conductivity coefficient of filler materials at the gap between copper blade and absorbent surface. In comparison between using MWCNT nano-fluid and water as the operating fluid, as well as using air, water, Benzene and Na-k alloy fluids separately in the air gap between the copper blade and the adsorbent surface, the collector's efficiency would be increased by $10.4,12.5,10.8$, and 10.8 , respectively.
\end{abstract}

\section{INTRODUCTION}

The sun is one of the energy sources that can supply the energy required for heating and cooling the buildings, as well as the energy needed for industrial processes (such as Seawater sweetening, etc.) [1]. Although Iran is one of the world's oilrich countries with huge natural gas reserves, implementation of solar plans in the cities and villages can lead to considerable saving in energy costs because of high solar radiation in most regions of the country. Solar radiation in Iran is estimated to be between 1800 and $2200 \mathrm{kWh} / \mathrm{m}^{2}$ year, which is, of course, above the global average. In addition, over 280 sunny days are reported averagely per year in Iran, which is noticeable [1]. There are various methods for using solar energy, but heating water using solar water heaters is known as one of the easiest and most economical methods. Solar collector is the main part of a solar water heater, which has different types (flat, evacuated tube, or concentrated). Various studies have been conducted regarding performance of evacuated tube collectors. Aboulmagd et al. [2] proposed efficiency of an evacuated U-tube solar collector using thermal analysis. Gao et al. [3] studied mathematical model for an evacuated U-tube solar collector and evaluated temperature distribution within length of the tube by fluid movement in longitudinal and radial manner. They also investigated impact of climatic conditions and important parameters affecting tube design such as diameter and mass flow and heat loss factor. Kim [4] tested thermal efficiency of an evacuated U-tube solar collector numerically and experimentally. In this collector, the air was used as the operating fluid and four different absorbent tube shapes were used for extracting the best shape with high efficiency. Naik [5] studied impact of mass flow, input temperature, collector length, and ambient temperature on thermal performance of the collector using mathematical model of an evacuated U-tube solar collector and selecting water as the operating fluid. The findings showed that input fluid temperature, collector length, and solar radiation had the highest impact on the collector efficiency and performance. Natarajan et al. [6] showed that thermal conductivity coefficient is increased by adding multi-wall carbon particles to the base fluid and increases efficiency of the collector. Thermal efficiency of an evacuated tube collector was calculated based on energy balance and loss energy and the effect of energy loss factor from each of the levels on the collector's efficiency was investigated. Mishra [7] carried experimental analysis on evacuated collector with U-Tube at different operating conditions. The analysis of thermal performance carried at different temperature due to variation of solar intensity. Kalogirou [8] developed a model for solar domestic water heating systems using artificial neural networks (ANN`s). The model estimated the useful energy extracted from a solar water heating system and the temperature rise in the stored water under the stated physical parameters of the system and the weather conditions. Kalogirou and Panteliou [9] predicted the long-term system performance of a domestic thermosiphon type solar water heating system using an ANN model. Lalot and Lecoeuche [10] employed an ANN model for the system identification of solar collectors during service. Vajk [11] has suggested the consideration of model sensitivity with respect to discretization and structural realization and has introduced a tool for reducing the modelling error. Liangdong et al. [12] based on the energy balance for the glass evacuated tube solar collector with U-tube, the thermal performance of the 
individual glass evacuated tube solar collector investigated by analytical method. Gao et al. [13] analyzed the effects of thermal mass and flow rate on forced circulation solar hotwater system of water-in-glass and U-pipe evacuated tube solar collectors. Wang et al. [14] carried out experiment and simulation study on all-glass evacuated tubular solar air heater with simplified compound parabolic concentrator (CPC) and U-shaped copper tube. Zhang et al. [15] investigated experimental performance and comparative analyses based on heat extraction of direct-flow coaxial evacuated-tube solar collectors with and without heat shields. Bhowmik and Amin [16] introduced a new technology to improve the performance of the solar thermal collectors. The solar reflector used here with the solar collector to increase the reflectivity of the collector. A prototype of a solar water heating system was constructed and obtained the improvement of the collector efficiency around $10 \%$ by using the reflector.

Sudhakar et al. [17] studied the thermal performance of cylindrical screen mesh wick heat pipe using $\mathrm{Cu}$ nano-fluid as the working medium and optimize the working parameters using the Response Surface Methodology (RSM). The working parameters considered are heat input, angle of inclination and concentration of the copper nano particles in the copper nano-fluid. Sandlin and Khalik [18] designed a concentrating solar power (CSP) receiver use granular material -such as sand-as the heat transfer and energy storage medium. Early designs of particle heating receivers (PHR) utilize a falling curtain of particles which directly absorbs the concentrated solar radiation. Kim [19] investigated conditions of functioning in the above paper and studied impact of using various types of nano-fluid on thermal efficiency.

In the present work, thermal efficiency of an evacuated tube solar collector sample is calculated with a new approach at different performance conditions and then using sensitivity analysis, factors affecting the efficiency are identified. Dominance over the thermal resistance in the air gap between copper blade and absorbent surface (using Novel method) and filling the gap by fluids with higher thermal conductivity coefficient instead of air, using different nano-fluids instead of pure operating fluid and impact of mass flow rate, fluid input temperature, collector length, and severity of solar radiation on the collector's efficiency are investigated. Finally, optimal values of decision variables to achieve maximum collector's efficiency were specified using sensitivity analysis results and genetic algorithm.

\section{STATMENT OF PROBLEM AND GOVERNING EQUATIONS}

Figure 1 indicates schematic of solar collector under study. Enclosed-type Evacuated U-tube Solar Collector (EEUSC) can be used where higher temperature is needed because of considerable reduction in thermal energy loss. This type of collector is used in much equipment such as electricity generation, HVAC systems, food makers, water heaters, etc. In this type of collectors, high efficiency is produced in low cost by fluid movement within a copper U-shaped tube, where a copper blade (fin) around it acts as the fixed heat flux transfer to the operating fluid.

In this work, evacuated U-tube solar collector is investigated with the specifications mentioned in Table 1 at different working conditions to increase efficiency [18].

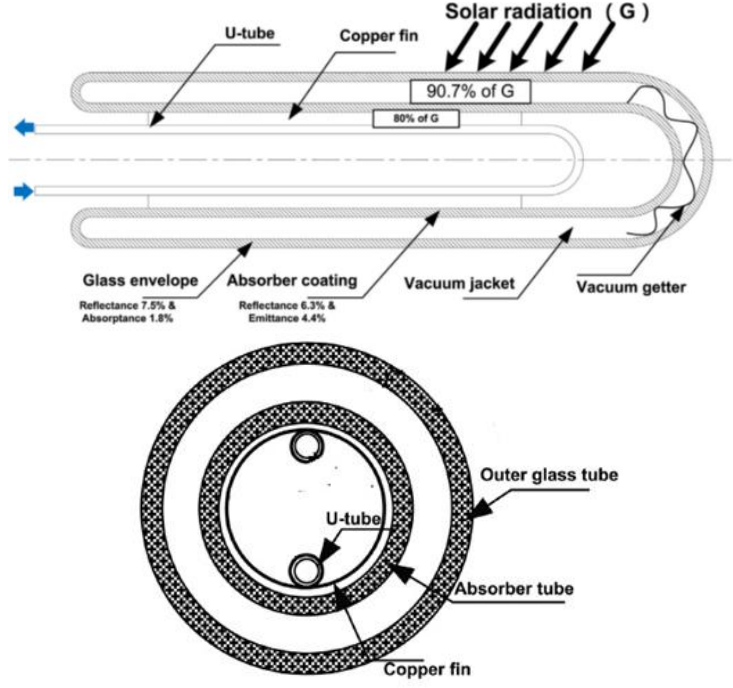

Figure 1. Schematic of a U-tube collector sample

Table 1. Specifications of EEUSC solar collector and its ambient conditions [18-19]

\begin{tabular}{|c|c|}
\hline Parameter & Value \\
\hline $\mathrm{D}_{g}:$ Outer Tube Outer Diameter (Glass Tube) & $47 \mathrm{~mm}$ \\
\hline $\mathrm{t}_{g}$ : Outer Tube Thickness & $2 \mathrm{~mm}$ \\
\hline$\varepsilon_{g}:$ Transmittance & 0.907 \\
\hline $\begin{array}{l}\mathrm{K}_{g} \text { : Thermal conductivity of Outer Tube } \\
\mathrm{K}\end{array}$ & $1.2 \mathrm{~W} / \mathrm{m}$ \\
\hline $\mathrm{D}_{P}:$ Inner Tube Outer Diameter (Absorber Tube) & $37 \mathrm{~mm}$ \\
\hline $\mathrm{t}_{P}:$ Outer Tube Thickness & $2 \mathrm{~mm}$ \\
\hline$\varepsilon_{P}:$ Emissivity of Absorber Tub & 0.06 \\
\hline $\begin{array}{l}\mathrm{K}_{P}: \text { Thermal conductivity of Absorber Tube } \\
\mathrm{W} / \mathrm{m} \mathrm{K}\end{array}$ & 1.2 \\
\hline $\begin{array}{l}\mathrm{L}_{C}: \text { Solar Collector Length } \\
\mathrm{mm}\end{array}$ & 1200 \\
\hline$\delta$ : Air Gap & $1.5 \mathrm{~mm}$ \\
\hline $\mathrm{t}_{\text {Cop }}$ : Copper Fin Thickness & $0.6 \mathrm{~mm}$ \\
\hline $\mathrm{D}_{b}:$ U-Tube Outer diameter & $8 \mathrm{~mm}$ \\
\hline $\mathrm{t}_{b}:$ U-Tube Thickness & $0.5 \mathrm{~mm}$ \\
\hline $\begin{array}{l}\mathrm{K}_{b} \text { : Thermal conductivity of U-Tube } \\
\mathrm{K}\end{array}$ & $307 \mathrm{~W} / \mathrm{m}$ \\
\hline $\begin{array}{l}\dot{m}: \text { Mass Flow } \\
\mathrm{kg} / \mathrm{s}\end{array}$ & 0.003 \\
\hline$T_{i}:$ Inlet Fluid Temperature & $293 \mathrm{~K}$ \\
\hline $\begin{array}{l}\mathrm{K}_{b f} \text { : Thermal Conductivity of base fluied } \\
0.6178 \mathrm{~W} / \mathrm{m} \mathrm{K}\end{array}$ & \\
\hline $\begin{array}{l}\mathrm{C}_{P-b f}: \text { Specific heat } \\
\mathrm{J} / \mathrm{kg} \mathrm{K}\end{array}$ & 4182 \\
\hline $\begin{array}{l}\mathrm{T}_{a}: \text { Ambient Temperature } \\
\mathrm{G} \text { : Solar radiation }\end{array}$ & $\begin{array}{r}283 \mathrm{~K} \\
1000\end{array}$ \\
\hline $\mathrm{W} / \mathrm{m}^{2}$ & \\
\hline $\begin{array}{l}\mathrm{I}=80 \% \mathrm{G} \\
\mathrm{W} / \mathrm{m}^{2}\end{array}$ & 800 \\
\hline
\end{tabular}

Thermal diagram related to the respective solar collector is shown in Figure 2. Using energy balance equation, total heat $\left(Q_{t}\right)$ is summation of energy loss from the external tube $\left(Q_{l}\right)$ and useful absorbed energy and transferred to the operating fluid $\left(Q_{u}\right)[20]$. 


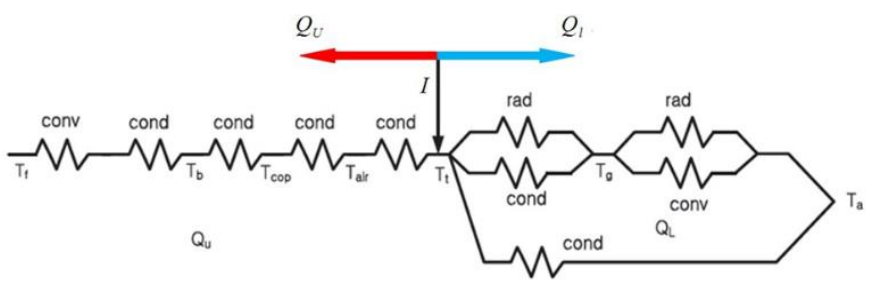

Figure 2. Thermal resistance diagram of respective collector

The useful energy absorbed by the solar collector is obtained by following equation:

$Q_{u}=A_{c}\left(I-U_{l}\left(T_{t}-T_{a}\right)\right), \quad I=G(\alpha \tau)_{a v e}$

where $(\alpha \tau)_{a v e}$ is multiplication of absorption coefficient of absorber and glass transmission coefficient. Calculation of heat loss from the collector requires calculation of heat loss factor from the collector and corners. Heat loss factor from outer tube surface is obtained from the following equation:

$U_{l}=U_{b}+U_{e}$

where $U_{b}$ is heat loss factor from absorber surface to the outer ambient and $U_{e}$ is loss factor from the corners and it is obtained from the following equation:

$U_{e}=\frac{(U A)_{p}}{A_{S}}=\frac{2 \pi k_{i n s}}{\operatorname{Ln} \frac{D_{o, i n s}}{D_{i, i n s}}}$

Heat loss factor from absorbent surface to the ambient, is obtained from the following equation:

$U_{b}=\frac{1}{\frac{1}{h_{g a}}+\frac{1}{h_{p g}}}$

In the above equation, $h_{g a}$ is coefficient of heat transfer from outer glass to the ambient, and includes radiative and conductive heat transfer. $h_{p g}$ is the coefficient of heat transfer between absorbent surface and glass tube, which includes radiation heat transfer and conductive heat transfer. Both of these coefficients can be obtained from the following equations:

$h_{g a}=h_{\text {conv }, g-a}+h_{\text {rad }, g-a}=\left[\varepsilon_{g} \sigma\left(\mathrm{T}_{g}{ }^{2}+T_{a}{ }^{2}\right)\left(T_{g}+T_{a}\right)\right]+\left[N u_{a} \frac{k_{a}}{D_{g}}\right]$

Where $h_{r a d, g-a}$ is factor of radiation heat loss from glass to the ambient, and $h_{\text {Conv, }, a}$ is convection heat transfer coefficient from glass to ambient. Nusselt number in Eq. (5) can be calculated from the following equations:

$$
\begin{aligned}
& N u=\left\{\begin{array}{lr}
0.4+0.5 \mathrm{Re}_{a}^{0.52} & 0.1<\mathrm{Re}_{a}<1000 \\
0.3 \mathrm{Re}_{a}^{0.6} & 1000<\mathrm{Re}_{a}<50000
\end{array}\right\} \\
& R e_{a}=\frac{u_{a} D_{g}}{v_{a}}
\end{aligned}
$$

$h_{p g}=h_{c o n d, p-g}+h_{r a d, p-g}=\left[\frac{2 \pi l k}{\ln \left(\frac{r_{o}}{r_{i}}\right)}\right]+\left[\frac{\sigma \varepsilon_{p}\left(T_{p}{ }^{2}+T_{g}{ }^{2}\right)\left(T_{p}+T_{g}\right)}{1+\frac{\varepsilon_{P} D_{P}}{\varepsilon_{g} D_{g}}\left(1-\varepsilon_{g}\right)}\right]$

where $h_{\text {cond }, p-g}$ is convective transfer coefficient between two glasses, which can be neglected considering the vacuum. According to studies by Tian [21], $h_{\text {Cond }, g-a}$ is considered equal to $12.7 \mathrm{~W} / \mathrm{m}^{2} \mathrm{~K}$. In the Eq. (8), $\sigma$ is Stefan-Boltzmann constant as $5.67 \times 10^{-8}$, and $\varepsilon_{P}$ and $\varepsilon_{g}$ are emission coefficients for absorbent surface and outer glass, respectively. The heat transferred to copper blade can be calculated by Eq. (9) using Figure 3.

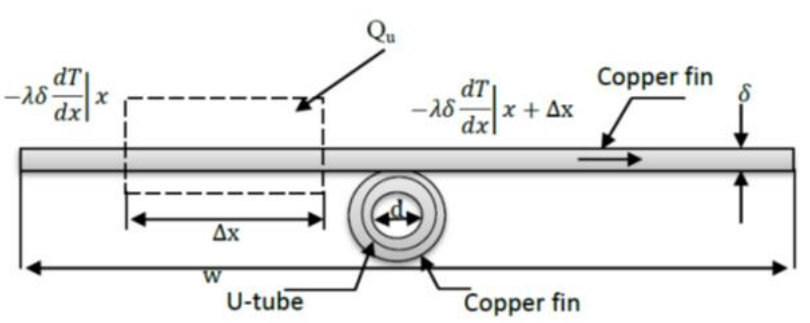

Figure 3. Element considered for analysis of copper blade temperature

$$
Q_{u}=\frac{T_{t}-T}{\frac{\delta_{a b}}{k_{a b}}+\frac{\delta_{c o m}}{k_{c o m}}}=\frac{T_{t}-T}{\frac{1}{C_{a}}}
$$

where $C_{a}$ is the coefficient dependent on the fillers (type of material in gap), com and $a b$ are the indexes related to the filler between absorbent surface and copper blade and absorber, respectively. With considering Fig. 3, the copper blade temperature can be obtained from the following equation:

$k \delta \frac{d^{2} T}{d X^{2}}+\mathrm{Q}_{u} \Delta X=0$

A homogeneous equation is obtained by replacement of $Q_{u \text {.max }}$ and simplification of above equation and considering following constant:

$$
\mathrm{T}(x)=A \cosh m x+B \sinh m x, m^{2}=\frac{U_{l}}{k_{f i n} \delta_{f i n}\left(1+\frac{U_{l}}{C_{a}}\right)}
$$


The heat transferred from around the U-tube and inside the tube can be calculated by the following equation considering boundary conditions and solving above equation:

$Q_{u}=\frac{T_{b}-T_{f, a v g}}{\frac{1}{h_{f u} \cdot \pi \cdot d . l}+\frac{1}{k_{c}}}$

where $k_{c}$ is thermal coefficient of copper blade on the tube [20]:

$k_{c}=\left[\frac{\ln \left(d_{2} / d\right)}{2 \pi l k_{\text {fin }}}+\frac{\ln \left(d / d_{1}\right)}{2 \pi l k_{\text {tube }}}\right]^{-1}$

In above equation, $d$ is the outer diameter, $d_{1}$ is the inner diameter of tube and $d_{2}$ is outer diameter of the blade. The heat absorbed by the collector is calculated by the following equation [20]:

$Q_{u}=W \cdot l \cdot F^{\prime}\left(I-U_{l}\left(T_{f, a v g}-T_{a}\right)\right)$

where $F^{\prime}$ is the collector's efficiency factor, which is an important constant in designing every collector, and it is calculated using following equation:

$$
F^{\prime}=\frac{\left(1 / U_{1}\right)}{W\left[\frac{1+\left(U_{1} / C_{a}\right)}{U_{l}((W-d) \mathrm{F}+\mathrm{d})}+\frac{1}{h_{f u} \cdot \pi \cdot d_{i}}+\frac{1}{k_{c}}\right]},
$$

Where $: F=\frac{\tanh (m(W-d) / 2)}{m(W-d) / 2}$

where $F$ is the standard fin efficiency for straight fin with rectangular profile and $h_{f u}$ is the coefficient of heat transfer between fluid and copper tube, and it is calculated by the following equation:

$$
h_{f u}=\frac{1}{\frac{1}{h_{n f}}+\frac{\delta_{\text {tube }}}{k_{\text {tube }}}}
$$

$h_{n f}$ is nano-fluid heat transfer coefficient, calculation of which will be described in the next section. The density, mass flow rate, specific heat coefficient, viscosity, Reynolds number, Nusselt number, conductivity, and convection heat transfer coefficients of nano-fluids with concentration $(\varphi)$ are obtained from the following equations, respectively:

$$
\begin{aligned}
& \rho_{n f}=(1-\varphi) \rho_{b f}+\varphi \rho_{s} \\
& \dot{m}=\rho_{n f} V A \\
& \left(C_{P}\right)_{n f}=\frac{(1-\varphi) \rho_{n f} C_{p_{(b f)}}+\varphi \rho_{S}\left(C_{P}\right)_{S}}{\rho_{n f}}
\end{aligned}
$$

$$
\begin{aligned}
& \mu_{n f}=\frac{\mu_{\text {water }}}{(1-\varphi)^{2.5}} \\
& \operatorname{Re}=\frac{4 \dot{m}}{\pi d \mu_{n f}}
\end{aligned}
$$

$$
N u= \begin{cases}1.953\left(\operatorname{Re} \operatorname{Pr} \frac{d_{i}}{x}\right)^{\frac{1}{3}}, & \left(\operatorname{Re} \operatorname{Pr} \frac{d_{i}}{x}\right) \geq 33.33 \\ 4.364+0.0722\left(\operatorname{Re} \operatorname{Pr} \frac{d_{i}}{x}\right), & \left(\operatorname{Re} \operatorname{Pr} \frac{d_{i}}{x}\right)<33.33\end{cases}
$$

$$
\left\{\begin{array}{l}
k_{n f}=k_{b f}(1-\varphi)+\beta k_{s} \varphi \\
\frac{k_{n f}}{k_{\text {Water }}}=\frac{k_{s}+2 k_{\text {water }}+2 \varphi\left(k_{s}-k_{\text {Water }}\right)}{k_{s}+2 k_{\text {water }}-\varphi\left(k_{s}-k_{\text {Water }}\right)}
\end{array}\right.
$$

$$
h_{n f}=\frac{N u k_{n f}}{d_{i}}
$$

The useful energy receivable by fluid is calculated by the following equation [20]:

$$
\begin{aligned}
& Q_{u}=F_{R} \cdot Q_{u, \max }=A_{c} F_{R}\left[G(\alpha \tau)-U_{l}\left(T_{f i}-T_{a}\right)\right], \\
& \text { Where : } F_{R}=\frac{\dot{m} C_{P}}{A_{c} U_{l}}\left[1-\exp \left(-\frac{U_{l} A_{c} F^{\prime}}{\dot{m} C_{P}}\right)\right]
\end{aligned}
$$

where $F_{R}$ is the collector heat removal factor. Extent of heat transfer to the operating fluid based on input and output temperatures is obtained from the following equation:

$$
Q_{u}=\dot{m}\left(C_{P}\right)_{n f}\left(T_{f o}-T_{f i}\right)
$$

Finally, solar collector's efficiency can be calculated using following equation [23]:

$\eta=\frac{Q_{u}}{A_{C} G}$

\subsection{Optimization using genethic algorithm and problem solving technique}

Genetic algorithm is implemented in different ways with various operators. The flowchart in Figure 4 (a) indicates different steps in the process of optimization by genetic algorithm. In the initial valuing, firstly some points of the search space are randomly selected and then they are coded (chromosome formation). Each of these chromosomes can be considered as an answer for the optimization problem. The number of selected chromosomes depends on the population considered for the problem. The objective function is calculated for each chromosome, and it is allocated. Collection of these chromosomes constitutes the primary generation. New generation is produced using the current generation in the generation production step. For this purpose, a pair of chromosome from the current generation with likelihood 
proportionate to the chromosome's objective function is selected (parent), and a new pair of chromosome (Childs) is produced by applying crossover and mutation operators. These Childs are put in the next generation. Selection, crossover, and mutation continue until the adequate number of Childs is produced for filling the new generation. Then, objective function is calculated for each new chromosome, and it is allocated. In the replacement phase, the new chromosomes
(Childs) replace the previous chromosomes (parents), i.e. the new generation replaces the previous generation. The rebuilding and replacement phases are repeated so that the optimal answer is closely enough to reach. The rate of approaching the optimal answer, which is the condition for the end of genetic algorithm, is determined by the user. For this, there are usually criteria that must be met.

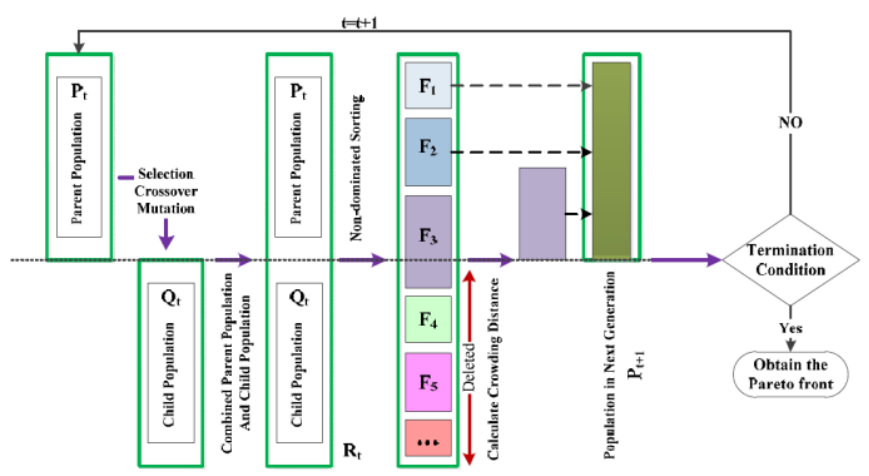

(a)

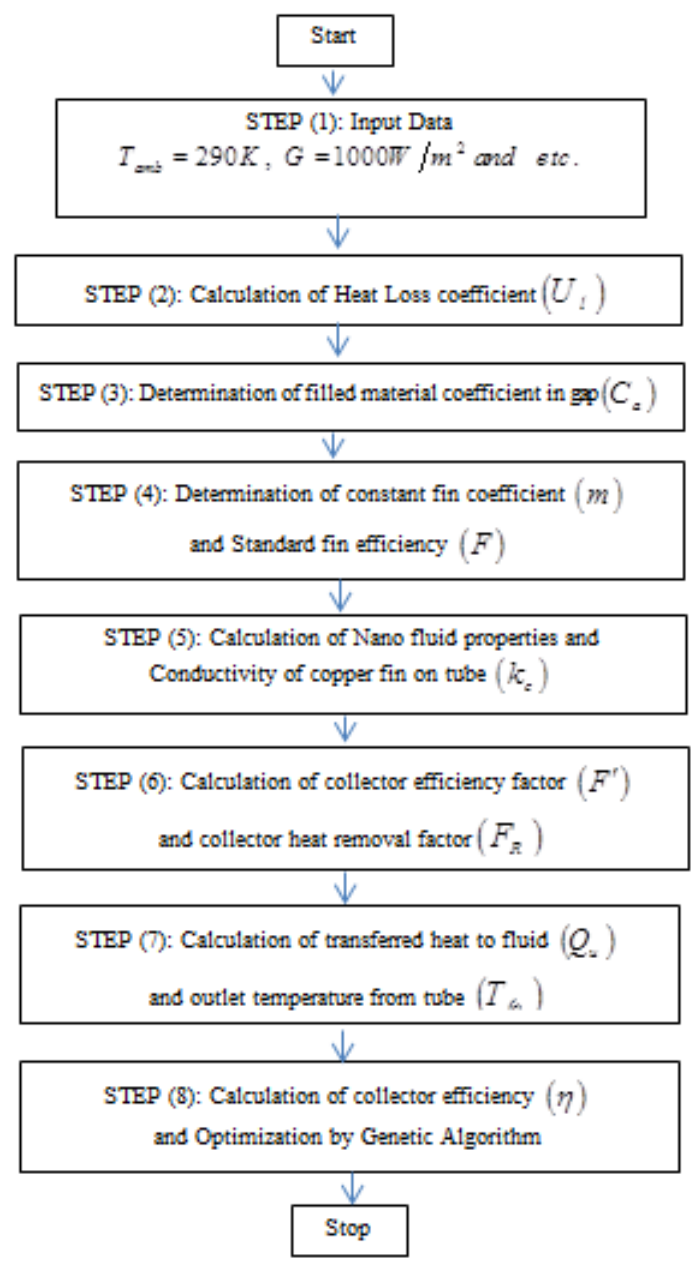

(b)

Figure 4. Flowchart (a) Optimization using genetic algorithm (b) Problem solving technique

These answers are referred to as Pareto optimal boundaries. In this study, an EEUSC solar collector consisting of two glass tubes, with evacuation between them, and the outer glass tube and the inner tube having an absorbent surface coating, are numerically thermally analyzed. A U-tube and a circular copper blade around it (for the uniformity and stability of thermal flux) is put in the collector, which pass the operating fluid. The problem can be solved as shown in algorithm in Figure 4 (b). 


\section{RESULTS}

In this section, the parameters affecting collector's efficiency, especially ultra-environmental factors (using nanofluid as the operating fluid, as well as use of fluids with higher thermal conductivity coefficient in the air gap between the absorbent surface and the copper blade) are investigated through studying thermal performance of evacuated U-tube solar collector with the given specifications in order to achieve optimal state.

\subsection{Validation and sensitivity analysis}

Calculations and research on EEUSC solar collector and the comparison with several other references at identical conditions (mass flow rate as $0.01 \mathrm{~kg} / \mathrm{s}$ and input fluid temperature as $40{ }^{\circ} \mathrm{C}$ ) suggest identical results with reference [18] and [19], results of which are given in Figures 5 and 6.

Investigation and test of thermal efficiency in collectors in all standards is especially important. Figure 7 indicates results of change in collector's efficiency in terms of heat loss factor $\left(T_{i}-T_{a}\right) / G$. The relation between thermal efficiency of collector and heat loss factor can be calculated using following equation:

$$
\left.\eta=F_{R}(\alpha \tau)-F_{R} U_{l}\left(\frac{T_{i}-T_{a}}{G}\right)\right)
$$

According to Equation (28), when values of $F_{R}(\tau \alpha)$ and $F_{R} U_{l}$ are constant, efficiency change in terms of heat loss factor would be as a direct line with inverse slope, equal to $-F_{R} U_{l}$ and intercept as $F_{R}(\tau \alpha)$ [12].

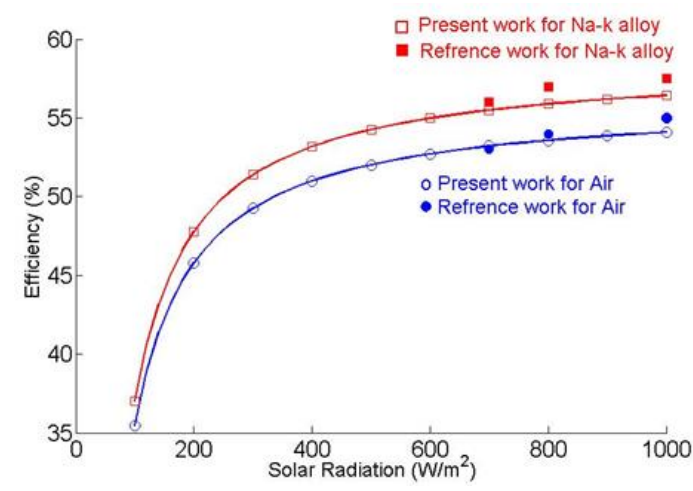

Figure 5. Comparison of thermal efficiency of solar collector using different materials at air gap (current work and results of reference [18])

As it is shown in figure 6, the collector's efficiency will be reduced by increasing the heat loss factor. This figure also indicates change in collector's efficiency in terms of $\left(T_{i}-T_{a}\right) / G$ coefficient for various types of nano-fluid compared to water. It is observed that the collector's thermal efficiency increases due to temperature difference using different nanofluids. In addition, the figure indicates that MWCNT nanofluid has highest efficiency compared to other fluids.

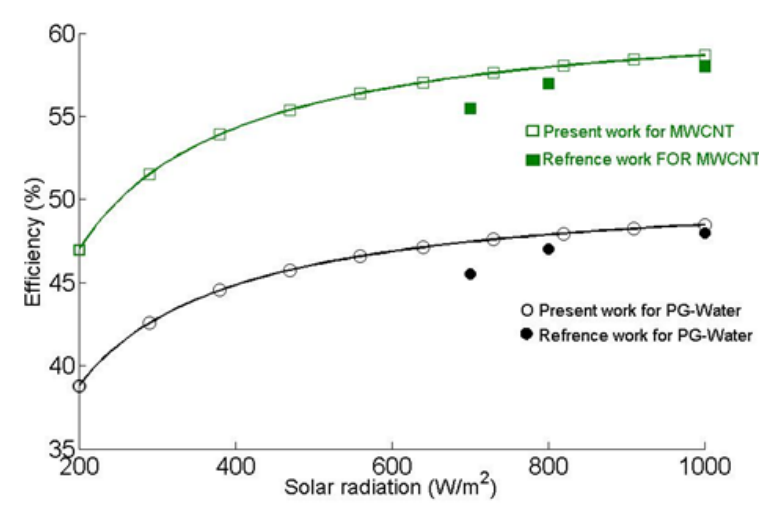

Figure 6. Comparison of thermal efficiency of solar collector using different nano-fluids and air fluid at air gap (current work and results of reference [19])

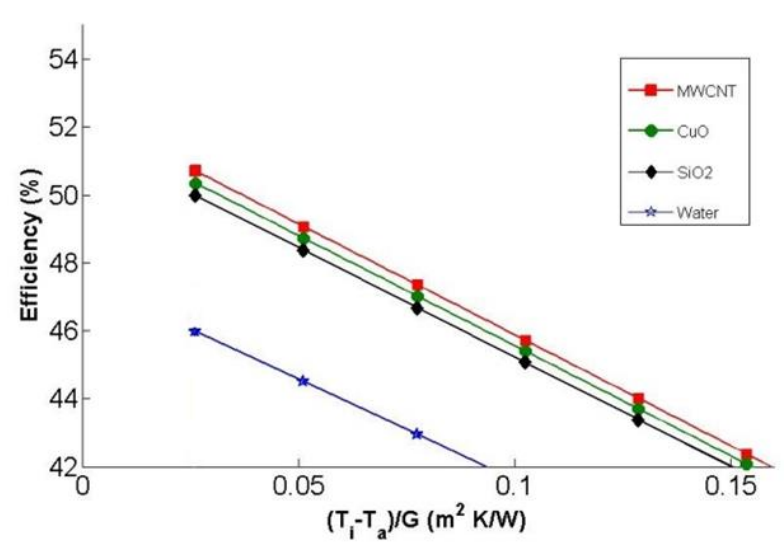

Figure 7. Collector's efficiency in terms of heat loss factor for different nano-fluids

The change in collector's efficiency at absorbent surface temperature $T_{P}$, at constant radiation $\left(G=1000 \mathrm{~W} / \mathrm{m}^{2}\right)$, ambient temperature $238 \mathrm{~K}$ and input fluid temperature $293 \mathrm{~K}$ depending on the type of filler fluid in the space between the absorbent surface and the copper blade $\left(C_{a}\right)$ is plotted in Figure 8 (a). As observed in the figure, increasing thermal conductivity coefficient of the filler fluid at the air gap increases collector's efficiency. It is also observed that by increasing thermal conductivity coefficient of the filler material at the space between copper blade and absorbent surface to above 35 (W/m.K), increasing solar collector's efficiency can be neglected. Figure 8 (b) indicates relationship between solar radiation and solar collector's efficiency for several types of filler at air gap. It is clear that replacement of air with Na-k alloy at radiation $100 \mathrm{~W} / \mathrm{m}^{2}$ increases efficiency by 2.3 percent, and at radiation $900 \mathrm{~W} / \mathrm{m}^{2}$, by 4 percent. Although using Na-K at air gap has highest efficiency, using water as the filler fluid at this space is recommended due to safety risks and economical saving in Na-K. In addition to increasing thermal efficiency by 4 percent, it is not costly and would not cause corrosion and rust in copper blade. 


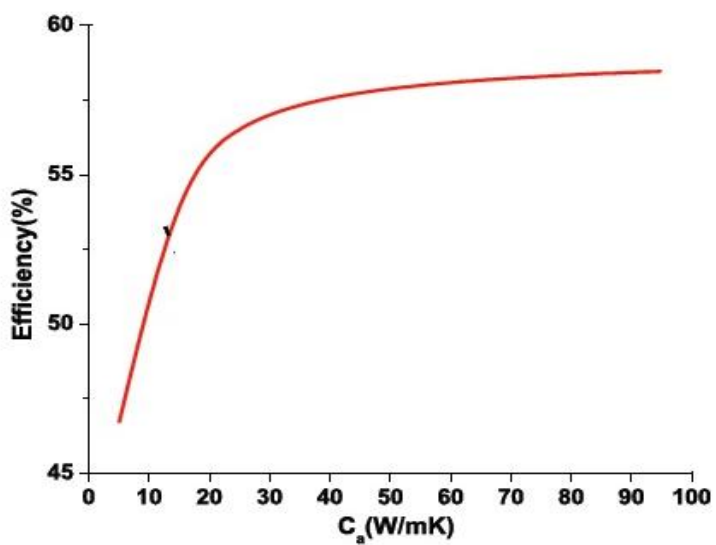

(a)

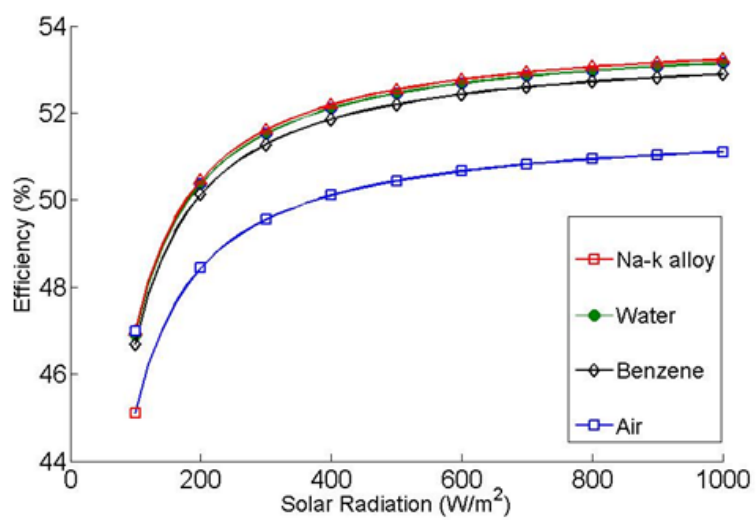

(b)

Figure 8. Change in collector's thermal efficiency with thermal conductivity coefficient of different fillers, (b) Solar radiation

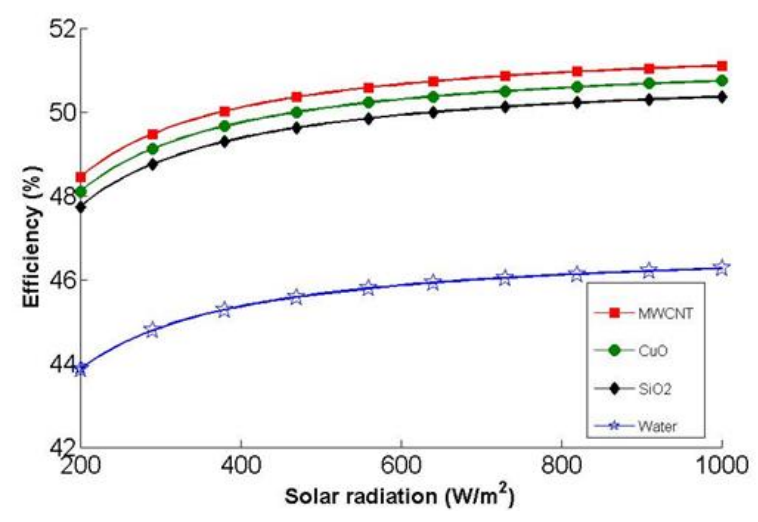

Figure 9. Change in collector's efficiency toward changes in solar radiation for different nano-fluids

Figure 9 indicates change in collector's efficiency at a fixed volumetric concentration of nano-fluid $(0.24 \%)$ in terms of solar radiation. Figure 9 represents increasing collector's efficiency by increasing radiation. At a constant ambient temperature, change in efficiency increases to the amount of radiation with a steep slope, and this slope gradually decreases with increasing radiation to ultimately reach a constant value. This suggests that in low levels of radiation, thermal flux is very low, which reduces the flow of heat transfer between the tube and operating fluid. Figure 9 also examines relationship between efficiency of solar radiation and different nano-fluids. It can be seen that in all solar radiation values, the collector's efficiency is higher than that of other fluids in case of using MWCNT operating fluid.

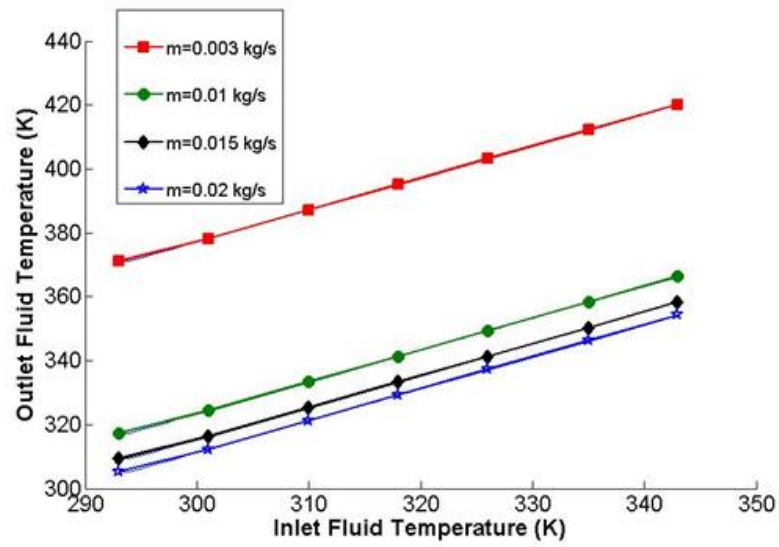

Figure 10. Changes in input and output temperature of collector fluid based on different mass flow rates

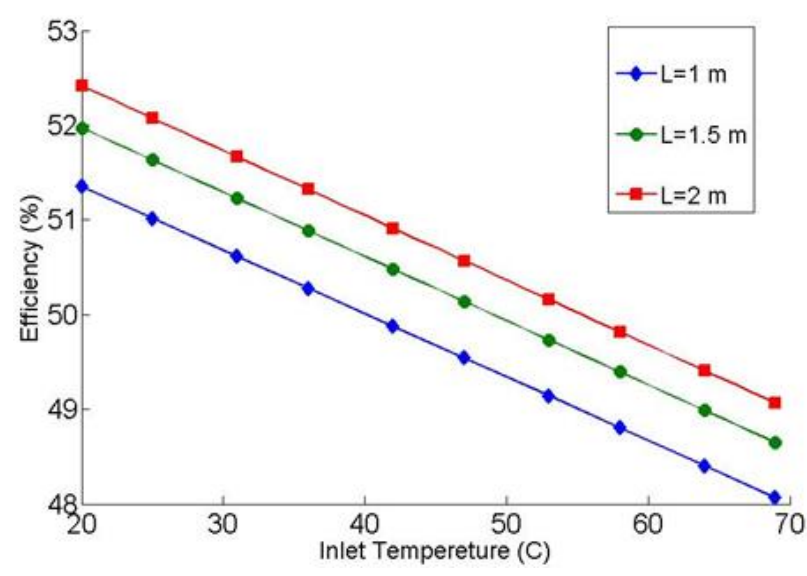

Figure 11. Changes in heat absorbed by collector fluid considering input temperature compared to the collector lengths

Impact of mass flow on output operating fluid temperature from the collector is shown in Figure 10. As observed, output operating fluid temperature from the collector is reduced by increasing mass flow. It denotes that in low mass flow values, higher time is spent on the relationship between operating fluid and walls of U-tube, leading to increasing output temperature. Thus, it is suggested that in the conditions governing the collector under discussion, flow with mass flow rate $0.003 \mathrm{~kg} / \mathrm{s}$ is used for higher thermal absorption from the tube walls. Impact of collector length on the absorbed heat by operating fluid and collector's efficiency is shown in Figure 11. The absorbed heat is reduced within a fixed length by increasing input temperature, and leads to reduced collector's efficiency. It is because heat transfer is increased by reduction in input temperature in a fixed radiation (Equation 18), and heat transfer resulting from convection heat transfer between nano-particles and operating fluid is reduced by increasing input temperature. Figure 11 also indicates that heat absorption capacity is increased by increasing collector length in a fixed input temperature; however, the increase would be trivial by increasing input temperature. Additionally, interaction between operating fluid and tube wall surface is increased by increasing collector length, leading to increased energy absorption and collector's efficiency. Nano-particles' volumetric concentration impact on properties of operating fluid such as density and thermal conductivity coefficient and specific heat coefficient is shown in Figure 12. It is observed 
that density and thermal conductivity coefficient of the operating fluid is directly related to volumetric concentration percentage of nano-particles, and it is increased by increasing the concentration. Nevertheless, specific heat coefficient (CP) is related to volumetric concentration percentage of nano-fluid.

Considering the calculations, efficiency values of solar collector at different conditions using MWCNT nano-fluid and water as the operating fluid are given in Tables 2 and 3, respectively. As observed in Tables 2 and 3, collector's efficiency is higher when MWCNT is used as the operating fluid compared to pure water. Also, using Na-k alloy at the air gap between copper blade and absorbent surface yields highest deficiency. It is seen that when MWCNT is used instead of water as the operating fluid and use of water, benzene, and $\mathrm{Na}$ $\mathrm{k}$ alloy at the air gap, thermal efficiency of the collector is increased by $10.4,12.5,10.8$, and 10.8 percent, respectively, compared to when the water is used as the operating fluid. Considering the results, it is clear that using MWCNT as the operating fluid and using Na-k alloy at the air gap leads to highest efficiency of the collector. However, it is better to use water as the filler fluid for the air gap for safety issues.

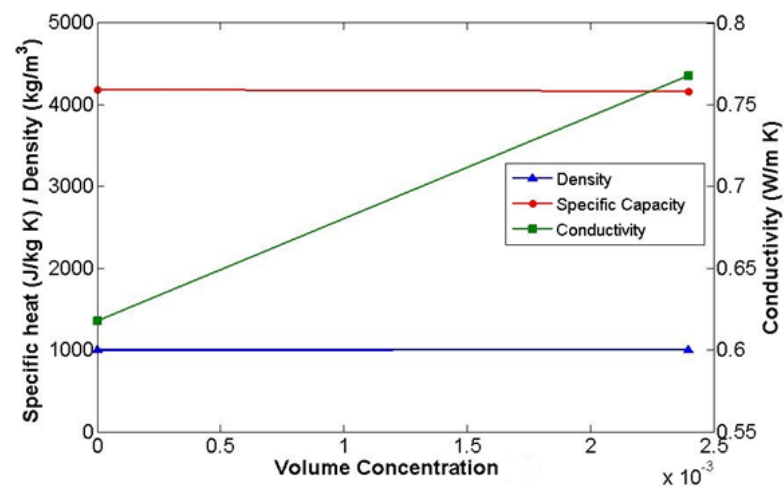

Figure 12. Diagram of nano-particles' volumetric concentration impact on properties of nano-fluid

Table 2. Solar collector's efficiency using MWCNT nano-fluid as operating fluid

\begin{tabular}{clllll}
\hline Nano-fluid & Parameter & Air & Water & Benzene & Na-k \\
\hline \multirow{2}{*}{ MWCNT } & $C_{a}$ & 16.22 & 244.73 & 90.56 & 577.4 \\
$\left(\mathrm{C}_{\mathrm{p}}\right)_{\mathrm{nf}}=4164.5$ & $F_{R}$ & 0.6472 & 0.6730 & 0.6698 & 0.6741 \\
$\mathrm{~kJ} / \mathrm{kg} \mathrm{K}$ & $Q_{u}(W)$ & 919.91 & 956.6 & 952.02 & 958.17 \\
& $\eta(\%)$ & 51.1 & 53.14 & 52.89 & 53.23 \\
\hline
\end{tabular}

Table 3. Solar collector's efficiency using water as operating fluid

\begin{tabular}{crrrrr}
\hline Nano-fluid & Parameter & \multicolumn{1}{c}{ Air } & Water & Benzene & Na-k \\
\hline Water & $C_{a}$ & 16.22 & 244.73 & 90.56 & 577.4 \\
$\left(\mathrm{C}_{\mathrm{p}}\right)_{\mathrm{nf}}=4182$ & $F_{R}$ & 0.5858 & 0.6069 & 0.6043 & 0.6078 \\
$\mathrm{~kJ} / \mathrm{kg} \mathrm{K}$ & $Q_{u}(W)$ & 832.72 & 826.6 & 858.95 & 836.95 \\
& $\eta(\%)$ & 46.26 & 47.92 & 47.7 & 48.1 \\
\hline
\end{tabular}

\subsection{Optimization using genethic algorithm}

Objective function of collector's thermal efficiency is considered for optimization of collector's thermal performance using genetic algorithm. The four parameters of mass flow rate of the collector, collector length $(\mathrm{L})$, solar radiation $(\mathrm{G})$, and heat loss factor are selected as decision parameters, with the specified intervals specified in Table 4.

Table 4. Decision parameters for optimizing collector's thermal performance

\begin{tabular}{cc}
\hline Decision variables & Range of variation \\
\hline Mass flow rate & $0.003 \mathrm{~kg} / \mathrm{s}<\dot{\mathrm{m}}<0.01 \mathrm{~kg} / \mathrm{s}$ \\
Length of collector & $1.1 \mathrm{~m}<L<1.8 \mathrm{~m}$ \\
Solar radiation Value & $200 \mathrm{~W} / \mathrm{m}^{2}<G<1000 \mathrm{~W} / \mathrm{m}^{2}$ \\
Heat Loss Coefficient & $0.02\left(\mathrm{~m}^{2} \mathrm{~K} / \mathrm{W}\right)<\left(\frac{T_{i}-T_{a}}{G}\right)<0.15\left(\mathrm{~m}^{2} \mathrm{~K} / \mathrm{W}\right)$ \\
Value & \\
\hline
\end{tabular}

Also, the setting parameters used to optimize the genetic algorithm are listed in Table 5.

By implementing calculations related to the system given conditions listed in Tables 4 and 5 as well as using singleobjective optimization using genetic algorithm, diagram related to the collector's efficiency is shown in Figure 13. The optimum decision variables are $\dot{m}=0.0055 \mathrm{~kg} / \mathrm{s}, L=1.45 \mathrm{~m}, G=680 \mathrm{~W} / \mathrm{m}^{2}$ and $\left(T_{i}-T_{a} / G\right)=0.04\left(m^{2} K / W\right)$ [24]. At this point the value of fitness function (thermal efficiency of collector) is equal to

Table 5. The setting parameters in the optimization process. Setting parameters value

\begin{tabular}{cc}
\hline Setting parameters & value \\
\hline Population size & 500 \\
Maximum number of generation & 400 \\
Minimum function tolerance & $10^{-5}$ \\
Probability of crossover & $90 \%$ \\
Probability of mutation & $1 \%$ \\
Number of crossover point & 2 \\
Selection process & Tournament \\
Tournament size & 2 \\
\hline
\end{tabular}




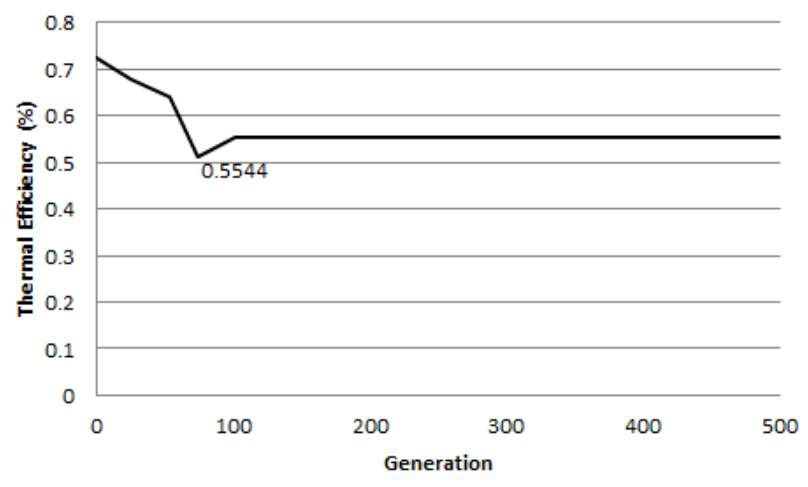

Figure 13. Single-objective optimization using genetic algorithm

\section{CONCLUSIONS}

In the present work, thermal performance of an evacuated U-tube solar collector via changing filler fluid of air gap between absorbent surface and copper blade and operating fluid in U-tube, which may have properties of a nano-fluid, was studied, and following results were obtained:

Results indicate that among nano-fluids used in this work, using MWCNT with concentration as the operating fluid inside U-tube with highest heat transfer coefficient between absorbent surface and operating fluid provides highest increase in the efficiency.

Collector's efficiency would be increased by increasing thermal conductivity coefficient of filler materials at the gap between copper blade and absorbent surface. Of course, increasing efficiency in using fluid with thermal conductivity coefficient above would be negligible.

In comparison between using MWCNT nano-fluid and water as the operating fluid, as well as using air, water, Benzene and Na-k alloy fluids separately in the air gap between the copper blade and the adsorbent surface, the collector's efficiency would be increased by $10.4,12.5,10.8$, and 10.8 , respectively.

Using MWCNT operating fluid and Na-k alloy at the air gap between copper blade and absorbent surface would bring highest efficiency. However, considering limitations in using this fluid (for safety problem), using water in this gap provides the best efficiency.

Mass flow rate, collector length, and solar radiation influence increasing collector's efficiency, however, input fluid temperature would have no significant impact on the efficiency.

\section{REFERENCES}

[1] Reyahi A, Taherian H. Heat water solar collectors in Iran. 4Th Building Fuel Optimatmum Seminar.

[2] Aboulmagd A, Padovan A. (2014). A new Model for the Analysis of performance. $3^{\text {rd }}$ International High Performance Buildings Conference at Purdue, paper 142. http://docs.lib.purdue.edu/ihpbc

[3] Gao Y, Fan R. (2006). Thermal performance and parameter analysis of a U-pipe evacuated solar tube collector. Solar Energy 107: 714-727. https://doi.org/10.1016/j.solener.2014.05.023
[4] Kim Y. (2014). Thermal performance comparichields of the glass evacuated tube solar collectors with shapes of absorber tube. Journal of Energy Research and Environmental Technology 2(3): 210-217.

[5] Kiran Naik B, Varshney P, Muthukumar, Somayaji C. (2016). Modelling and performance analysis of U type evacuated tube solar collector using different working fluids. Energy Procedia 90: 227-237. https://doi.org/10.1016/j.egypro.2016.11.189

[6] Natarajan E, Sathish R. (2009). Role of nano-fluids in solar water heater. The International Journal of Advanced Manufacturing Technology 42: 1-5. https://doi.org/10.1007/s00170-008-1876-8

[7] Mishra D. (2015). Experimental Analysis of thermal performance of evacuated U-Tube solar collector. Advance Physics Letter 2(3): 2349-1108. https://doi.org/10.1080/01430750.2015.1074612

[8] Kalogirou SA, Panteliou S, Dentsoras A. (1999). Modelling of solar domestic water heating system using artificial neural networks. Solar Energy 65(6): 335-342. https://doi.org/10.1016/S0038-092X(99)00013-4

[9] Kalogirou SA, Panteliou S. (2000). Thermosiphon solar domestic water heating system: Long-term performance prediction using artificial neural networks. Solar Energy 69(2): $\quad$ 163-174. https://doi.org/10.1016/S0038092X(00)00058-X

[10] Lalot S, Lecoeuche S. (2001). Identification of solar collectors during service using artificial neural networks. Proceedings of the ISES 2001 Solar World Congress, p. 128. https://doi.org/10.13140/2.1.2336.3848

[11] Vajk I. (1999). Sensitivity of non-linear dynamic modelling. Proceedings of the 14th World Congress of IFAC, Beijing, China, pp. 19-24. https://doi.org/10.1016/S1474-6670(17)56647-1

[12] Ma LD, Lu Z, Zhang J, Liang R. (2010). Thermal performance analysis of the glass evacuated tube solar collector with U-tube. Building and Environment 45: 1959-1967. https://doi.org/10.1016/j.buildenv.2010.01.015

[13] Gao Y, Zhang Q, Fan R, Lin X, Yu Y. (2013). Effects of thermal mass and flow rate on forced-circulation solar hot water system: Comparison of water-in-glass and Upipe evacuated-tube solar collectors. Solar Energy 98: 290-301. https://doi.org/10.1016/j.solener.2013.10.014

[14] Wang PY, Guan HY, Liu ZH. (2014). High temperature collecting performance of a new all-glass evacuated tubular solar air heater with U-shaped tube heat exchanger. Energy Conversion and Management 77: 315-323. https://doi.org/10.1016/j.enconman.2013.08.019

[15] Zhang X, You S, Ge H. (2014). Thermal performance of direct-flow coaxial evacuated-tube solar collectors with and without a heat shield. Energy Conversion and Management 84: 80-87 https://doi.org/10.1016/j.enconman.2014.04.014

[16] Bhowmik H, Amin R. (2017). Efficiency improvement of flat plate solar collector using reflector. Energy Reports 3: 119-123. https://doi.org/10.1016/j.egyr.2017.08.002

[17] Sudhakar G, Lakshmi P. (2015). An experimental analysis on thermal performance of cylindrical screen mesh wick heat pipe with CUO Nano-fluid using Response Surface Methodology. Int. J. Engg. Res. \& Sci. 
https://doi.org/10.1016/j.ijmultiphaseflow.2015.02.006

[18] Sandlin M, KhaliK SI. (2018). A study of granular flow through horizontal wire mesh screens for concentrated solar power particle heating receiver applications Part I: Experimental studies and numerical model development. Solar $\quad$ Energy 169 : 1-10. https://doi.org/10.1016/j.solener.2018.03.036

[19] Kim H. (2016). Theoretical investigation of the efficiency of a U-Tube solar collector using various nano-fluids. Journal of Mechanical Science and Technology 30(2): https://doi.org/10.1016/j.energy.2015.11.021

[20] Duffie JA, Bechman WA. (1980). Solar engineering of thermal processes. New York: John Wiley \& Chields.

[21] Tian Q. (2007). Thermal performance of the U-type evacuated glass tubular solar collector. Build Energy Environ 26(3): 51e4 [in Chinese]. https://doi.org/10.1109/MACE.2010.5535436

[22] ArturoAlfaro-Ayala J, Martínez-Rodrígueza G, PicónNúñeza M, Uribe-Ramíreza AR, Gallegos-Muñozb A. (2015). Numerical study of a low temperature water-inglass evacuated tube solar collector. Energy Conversion and Management 94: 472-481. https://doi.org/10.1016/j.enconman.2015.01.091

[23] Yadav M, Saikhedkar DNK. (2017). Simulation modeling for the performance of evacuated tube solar collector. Int. J. of Innovative Research in Science, Engineering and Technology 6(4): 5634-5642. https://doi.org/10.15680/IJIRSET.2017.0604120

[24] Jaegler Y. Jaegler A., (2017). The CONWIP Production Control System. Classification and discussion of current and future research avenues. Journal Européen des Systèmes Automatisés 50(3): 1-25. https://doi.org/10.3166/jesa.2018.00001

$A_{C} \quad$ Collector cross section $\left(\mathrm{m}^{2}\right)$

$C_{p} \quad$ Specific heat capacity $(\mathrm{J} / \mathrm{kgK})$

$D \quad$ Tube diameter (m)

$F \quad$ Blade standard efficiency

$F^{\prime} \quad$ Collector efficiency factor

$F_{R} \quad$ Heat loss factor

$G \quad$ Solar radiation $\left(\mathrm{W} / \mathrm{m}^{2}\right)$

$h_{g a}$ Thermal conductivity coefficient of convection from outer glass to ambient $\left(W / m^{2} K\right)$

$h_{p g} \quad$ Thermal conductivity coefficient of convection from absorbent surface to outer glass $\left(W / m^{2} K\right)$

Pr Prandtl number

$Q_{u} \quad$ Energy absorbed by collector $(W)$

Re Reynolds number

$T_{f} \quad$ Average fluid temperature $(K)$

$T_{i} \quad$ Input fluid temperature $(K)$

$T_{o} \quad$ Output fluid temperature $(K)$

$T_{p} \quad$ Absorbent surface temperature $(K)$

$T_{g} \quad$ Glass cover temperature $(K)$

\section{Greek symbol}

$\alpha \quad$ Absorption coefficient of absorber

$\varepsilon_{g} \quad$ Emission coefficient of glass cover

$\varepsilon_{p} \quad$ Emission coefficient of absorber

$\eta \quad$ Efficiency (\%)

$\tau \quad$ Glass transmission coefficient 